\title{
Designing Small Scale Tomato Processing Machine and to Evaluate Proximate Composition
}

\author{
Shah Monarch $\mathbf{J}^{1 *}$ and Shah Harshada $\mathbf{J}^{\mathbf{2}}$ \\ ${ }^{1} I F C$, GIDC VVN, Gujarat, India. \\ ${ }^{2}$ M.B.Patel Science College, Gujarat, India \\ *Corresponding Author: Shah Monarch J, IFC, GIDC VVN, Gujarat, India.
}

Received: June 20, 2019; Published: September 09, 2019

DOI: 10.31080/ASAG.2019.03.0641

\begin{abstract}
Tomato products such as puree and ketchup are used for the preparation of many food products which may include frozen food, pasta topping and pizza toppings etc. Good quality tomato based products with good solid content is manufactured and the viscosity of the produce is derived from the combination of water with the fibrous strands in the tomato paste and the gelling effect of pectin found naturally in tomatoes. This work facilitates home preparation and to prepare product efficiently at the level of food restaurants, wanders, cafeterias etc. Hygienically and pure common product (with and without preservatives) with assured quality of many eateries. The ketchup which already used are costlier and full of preservatives which is not preferable for human health whereas this machine produces $100 \%$ pure and hygienic ketchup without class II preservatives and it is cheaper also. This machine may be used for continuous production of ketchup. Only one person can handle the machine.
\end{abstract}

Keywords: Machine; Tomato; Ketchup

\section{Introduction}

Tomato ranks third in production after Potato (first) and Onion (second) in India and it ranks second after potato in the world.

World scenario [1]

The countries which cultivates majority of tomatoes are Italy, Turkey, China, USA, India and Egypt. Total area of land under which tomatoes are cultivated is 458.2 lakh hectors which produces about 1505138.13 lakh tons of tomatoes. It gives productivity of about 32.8 tons per hector.

In states like Gujarat and Maharashtra tomatoes are available throughout the year in one pocket or the other. By adopting best agro techniques, the tomatoes can be made available throughout the year.

\section{Consumption}

The tomatoes are edible, often red in color, kind of berry of the plant Solanum lycopersicum, commonly known as a tomato plant. The species was mainly originated in western part of South America.

Month wise availability of Tomato [2]

\begin{tabular}{|l|l|}
\hline Period of Harvest & \multicolumn{1}{|c|}{ Areas } \\
\hline January- March & $\begin{array}{l}\text { Bihar, Eastern UP, MP, Orissa, foot hills } \\
\text { of Uttarakhand, Andhra Pradesh, Assam }\end{array}$ \\
\hline April- May & Haryana, Punjab, Karnataka, Rajasthan \\
\hline June-July & $\begin{array}{l}\text { H.P. Uttarakhand, Tamil Nadu, Punjab, } \\
\text { Gujarat }\end{array}$ \\
\hline August-September & $\begin{array}{l}\text { Andhra Pradesh, Himachal Pradesh, } \\
\text { Uttarakhand, Maharashtra, Gujarat }\end{array}$ \\
\hline $\begin{array}{l}\text { October- } \\
\text { November }\end{array}$ & Chattisgarh, Tamil Nadu \\
\hline December & $\begin{array}{l}\text { Andhra Pradesh, Rajasthan, Chattisgarh, } \\
\text { Madhya Pradesh, Orissa, Rajasthan }\end{array}$ \\
\hline
\end{tabular}

\section{Table a}

Indian scenario

There is a sizeable increase in acreage and production of tomato in India. The increase in cultivation from 596.0 thousand hectors in 2006-07 to 865.0 thousand hectors in 2010-11 itself gives the idea about growth in tomato based market. In terms of production of crop, it has increased from 100.55 to 168.26 lakh tons.

Details of grade and sizing of Tomatoes [AGMARK standard] [3] 


\begin{tabular}{|c|c|c|c|}
\hline $\begin{array}{c}\text { Grade } \\
\text { Designation }\end{array}$ & Grade Requirements & $\begin{array}{c}\text { Provision } \\
\text { concerning sizing }\end{array}$ & Grade Tolerances \\
\hline 1 & 2 & 3 & 4 \\
\hline Extra class & $\begin{array}{l}\text { Tomatoes of superior quality have firm flesh and must be } \\
\text { characteristics of the variety as regards shape, } \\
\text { appearance of the produce, the quality, }\end{array}$ & As per table $\mathrm{A}$ & $\begin{array}{l}5 \% \text { by number or weight [3] of toma- } \\
\text { toes not satisfying the requirement of } \\
\text { the grade, but meeting class I coming } \\
\text { within the tolerances of that grade. }\end{array}$ \\
\hline Class I & $\begin{array}{l}\text { Tomatoes shall be of good quality. They shall have } \\
\text { reasonably firm flesh and shall be characteristics of the } \\
\text { variety as regards shape, appearance and development. } \\
\text { They must free of cracks and visible green back. The } \\
\text { following slight defects may be there provided these do } \\
\text { not affect the general appearance of the produce, the } \\
\text { quality, the keeping quality and the presentation in the } \\
\text { package. } \\
\text { - A slight defect in shape and development; } \\
\text { - A slight defect in colouring; } \\
\text { - Slight skin defects; } \\
\text { - Very slight bruises; } \\
\text { - "ribbed" tomatoes may show: No excessive pro- } \\
\text { - tuberances; } \\
\text { - Small nonlignified umbilical scars } \\
\text { - Suberization of the stigma upto } 1 \text { sq. cm } \\
\text { No more than } 1 \text { headed scar } \\
\text { Umbilical lignified scars not greater than } 1 \text { sq.cm } \\
\text { or linear scar no longer than } 2 / 3 \text { rd of the great- } \\
\text { est diameter of the fruit }\end{array}$ & As per table $\mathrm{A}$ & $\begin{array}{l}10 \% \text { by number or weight of toma- } \\
\text { toes not satisfying the requirements } \\
\text { of the grade, but meeting those of } \\
\text { class II or, exceptionally, coming } \\
\text { within the tolerances of that grade. }\end{array}$ \\
\hline Class II & $\begin{array}{l}\text { Tomatoes shall be reasonably firm flesh and shall be } \\
\text { characteristic of the variety (but may be slightly less } \\
\text { firm than in class I) and must not show unhealed cracks. } \\
\text { Following defects may be there provided the tomatoes } \\
\text { retain their essential characteristics as regards the } \\
\text { quality, the keeping quality and presentation. } \\
\text { - Defects in shape, development and colouring; } \\
\text { - Skin defects or bruises, provided the fruit is not } \\
\text { - } \quad \text { Heriously affected; } \\
\text { - "ribbed" tomatoes may show } \\
\text { - More pronounced protuberances but without } \\
\text { - being misshapen; One umbilicus; } \\
\text { Umbilical lignified scars not greater than } 2 \text { sq. } \\
\text { - Fine blossom scar in elongated form. }\end{array}$ & As per table A & $\begin{array}{l}10 \% \text { by number or weight of } \\
\text { tomatoes not satisfying the require- } \\
\text { ments of the grade, but meeting the } \\
\text { minimum requirements. In case of } \\
\text { trusses of tomatoes, } 10 \% \text { by number } \\
\text { or weight of tomatoes detached from } \\
\text { the stalk. }\end{array}$ \\
\hline
\end{tabular}


In existing market tomato ketchup is used in many products including frozen foods, pasta ketchup, pizza toppings, Burgers and puffs and many more products. Premium quality ketchups with high solids content derive their viscosity from a combination of water of the fibrous strands in the paste and the gelling effect of pectin found naturally in tomatoes.

In some countries like United Kingdom, Australia, New Zealand, and South Africa, the term tomato sauce is used to describe product similar to tomato ketchup. In some of these countries, both terms are used for the condiment [4].

Tomato ketchup is also used to prepare Tomato sauce (also known as Neapolitan sauce, salsa roja in Spanish, or salsa di pomodoro in Italian) can refer to a large number of different sauces made primarily from tomatoes, usually to be served as part of a dish, rather than as a condiment. Tomato sauces are used not only in meat and vegetables but also in Mexican salsas or sauces for pasta dishes. Tomatoes have very tremendous flavor, high moisture content, soft structure which breaks down easily, and the right composition of mixture is used to thicken it to form sauce. The natural pactin present in tomatoes make it to thick sauce when it is cooked. These qualities of tomatoes make them ideal to make simple and appealing tomato ketchup and various sauces.

Processing of tomatoes is useful to manufacture variety of products including tomato puree, tomato paste, tomato ketchup, sliced and diced tomatoes, ketchup, bell peppers and various other sauces seasoned with fresh or dry garlic paste, basil seeds, oregano seeds, paprika seeds, crushed red pepper, parsley and olive oil.

The simple recipe to make tomato sauce is just to cook chopped tomatoes and simmered until it loses its raw flavor and further it is seasoned with salt, or other herbs or spices mentioned above. In another way, tomato skins may be scalded and peeled according to texture required and tomato seeds can be removed for aesthetic purposes, leaving just the tomato flesh and pulp. Many other products like tomato soup with various additional flavors can be made from tomato sauce.

This work facilitates home preparation and to prepare product efficiently at the level of food restaurants, wanders, cafeterias etc. Hygienically and pure common product (with and without preservatives) with assured quality of many eateries. However, capacity can be increased using same mechanisms according to requirements.
The present invention relates to a tomato processing machine. More particularly it relates to processes tomato in various type of products such as soup, puree, sauce, ketchup, pulp, and squash and like also process for preparation thereof.

The ketchup which already used are costlier and full of preservatives which is not preferable for human health whereas this machine produces $100 \%$ pure and hygienic ketchup without class II preservatives and it is cheaper also.

\section{Objectives of the invention}

1. The main objective of present invention is to launch tomato processing machine; wherein various products can be processed/manufactured in a single machine.

2. Another objective of the present invention is to make a hygienic, cost efficient and nutrition rich products without addition of chemical preservative by successful application.

3. Yet another objective of present invention is to provide small scale machine, which can manufacture product outside malls, restaurants, gardens like.

4. And yet another objective of present invention is that this will make various products available in different variety using single machine which is not available in market till the date.

\section{Methodology:}

\section{Methods and Materials}

- Tomatoes are procured from local market after interval of 15 to 20 days. Sound tomatoes were selected and processed using designed Machin.

- $1 \mathrm{~kg}$ tomatoes were feed into part 1 of machine. Process for $10 \mathrm{~min}$. auto transfer to part-2. And last at part 3. Add 4.0 g seasonings including onion, garlic and cloves. Add 4 gm salt and $400 \mathrm{~g}$. of sugar at point 6. process for $5 \mathrm{~min}$. Let the equipment process. The ketchup will be ready within 30 minutes.

- You will get $100 \%$ Pure and Natural fresh ketchup which will weight around $1.2 \mathrm{~kg}$, free from preservatives and color.

- Chemical analysis of the product was carried out as per protocols of AOAC [5].

\section{Machine equipment and accessories}

This machine is equipped with safety fuses, temperature indicator and controller and its compact and its design makes it looking attractive so in case of selling outside mall and restaurants, 
consumer will be attracted due to noise free operation and healthy, hygienic, nutrient rich and cost efficient products.

This equipment is divided in such a manner that we have to feed ingredients according to required final products, in machine it quantity is rectified, mixed, processed and it worked in specific manner under controlled parameters and it automatically makes the final product and makes it ready to be sold in market.

This machine may be used for continuous production of ketchup. Only one person can handle the machine.

\section{Description of the invention}

This machine is basically divided into three units

First, boiling, unit is basically used to boil the tomatoes. Bottom part of unit which contains water, and heating coil. Middle part which have pores, which passes steam to tomatoes, tomatoes are curried by this part and upper part which have tomato inlet for input of tomatoes.

Second, grinding unit is basically used to crush the tomatoes. First part of unit collects tomatoes from boiling, unit and transferees it to grinding machine. Second part has small holes for separation of puree and tomato seeds and skin. This part contains grinder inside the chamber. Here grinder is useful for not only grinding of tomatoes but also as agitator and third part which contains puree collecting vassals.

Third, Evaporation unit is useful for evaporating water from extract and adding sugar and spices for making different product as needed. This unit has heating mechanism and agitation mechanism for mixing and none sticking of tomato particles. All the parameters including temperature, pressure and time is controlled. It also extracts the flavors from the dry and wet ingredients and non-stick vessel or jacketed vessel may be used for the same.

\section{Brief description of the drawings}

This invention is illustrated in the accompanying drawings, throughout which like reference indicate corresponding parts in the various figures. This is a first kind of innovation which can process ketchup and products thereof at small scale.

Figure 1 shows diagram for boiling unit in which tomato is fed through tomato inlet and it is boiled with help of heating system, this heating system may be electric/mechanical/thermal/gas/ fuel or any of type thereof. This unit boils tomato and through nob, tomato is transferred. This unit is equipped with water level indicator so as to maintain constant water level in the boiling unit and through automatic door, tomato is transferred to second unit.

\section{Description of preferred embodiments}

Referring to the drawings, figure 1, it shows inlet (1) from which we feed the tomatoes which are free from insects and pesticides. This unit is particularly designed for boiling of tomatoes so as to loosen the peel. (2) Shows the tomatoes which are in the unit above the boiler steam plate (5) having small holes and (3) shows the hatch window for transferring tomatoes in second window. (4) Indicates top cover to avoid steam coming out to the chamber and (6) is water as medium of generation of steam (10), which helps in boiling and killing surface pathogens. Further, (7) shows heating mechanism. It may be electric/solar or any of the fuel powered and is used to generate the steam from water. (8) and (9) Indicates water level indicator which maintains constant water level in boiler through attached ball probe and feed water tank. Here, (11) shows

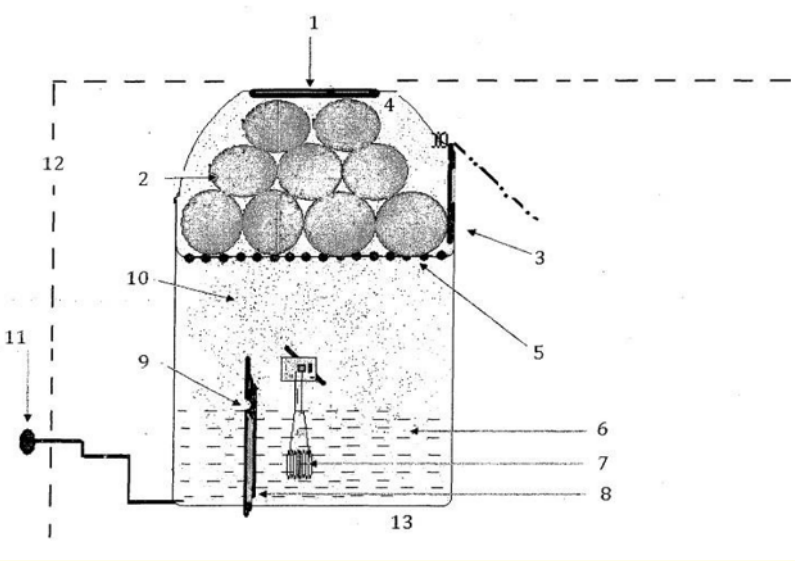

Figure 1

Mob arrangements which when moved/pressed/operated, it tilts the boiling unit and opens hatch window so as to transfer tomatoes in second unit.

Figure 2 represents tomato collecting and crushing unit, in which boiled tomatoes are crushed. It also separates seeds and peel of tomato and puree is collected in collecting vessel and is further transferred to next section.

\section{Description of preferred embodiments}

Figure 2 shows the tomato grinding and puree separation mechanism where (1) is tomato collector which comes from first 
unit and (2) shows the tomato whose skin is loosened. (3) shows motor with attached modified blades. (6) so as to crush the tomatoes and separate peel at the same time. (5) indicates small

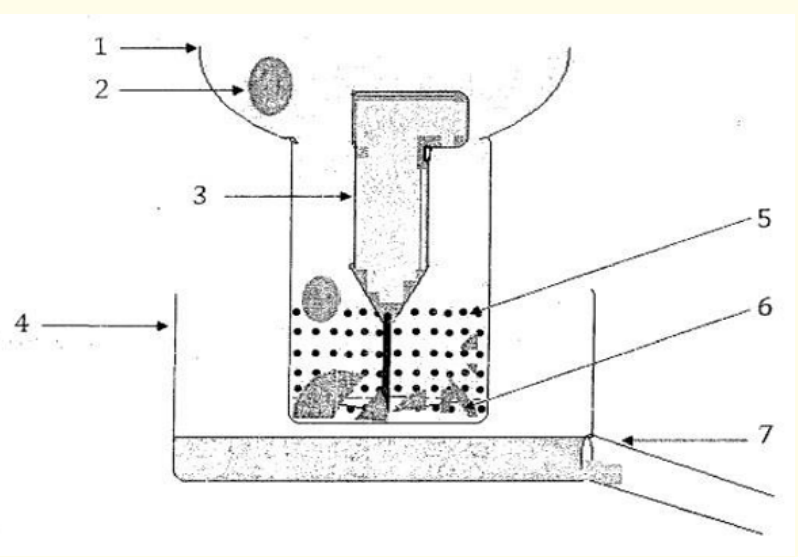

Figure 2

holes through which puree can pass and seeds can't and due to centrifugal force acting on puree, it passes through holes and gets collected in puree collector (4). Further, it is transferred to third unit via pipe (7).

Figure 3 Shows evaporation unit, which receives puree and heat it with continuous stirring to achieve desired concentration of the final product. For different products from soup to ketchup the consistency and concentration varies. Here provision for addition of spices is arranged to prepare product in different taste variants, (i.e. Sweet/Spicy).

\section{Description of preferred embodiments}

Figure 3 Shows evaporation unit where temperature is maintained through controller (1) and puree is constantly agitated

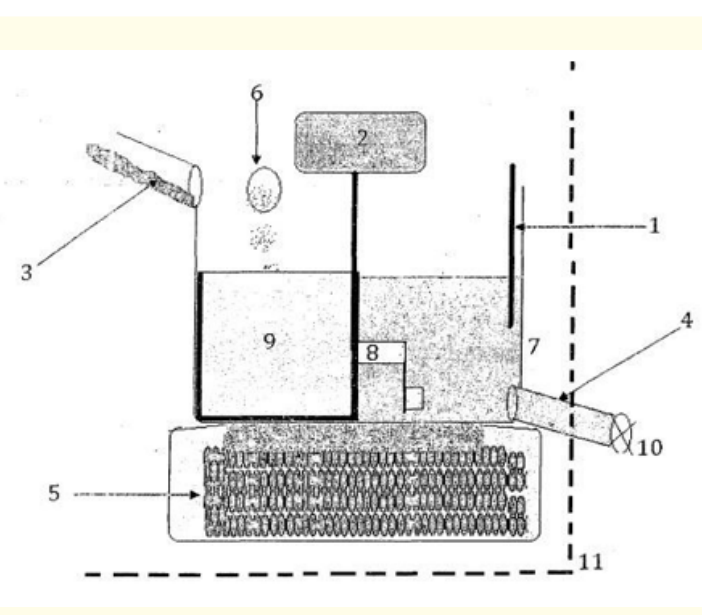

Figure 3

with agitator (2) having specially designed blades for extraction of wet and dry ingredients flavor. (3) shows puree coming from second unit and (4) is final product output pipe (5) is heating mechanism which may be electric/solar or any of fuel powered and (6) shows moreish mixture pipe for addition of essential ingredients to puree in vessel (7). (8) and (9) is blade components for scrapping and extracting flavor of wet and dry ingredients. (10) Is valve to control the output of final product and (11) shows outer body of the unit.

This is a first kind of innovation which can process ketchup and products thereof at small scale.

\section{Result and Discussion}

Study includes results of three trials carried out using our designed machine.

Tomatoes processed indicates non- significant alteration in their nutritive value. Total carbohydrate content for sample 2 is slightly higher than other trial. Moisture and protein content is also

\begin{tabular}{|c|c|c|c|c|}
\hline $\begin{array}{c}\text { Nutrient/Trial } \\
\text { of sample }\end{array}$ & Moisture [gm] & Protein [gm] & Carbohydrate [gm] & $\begin{array}{c}\text { Energy [Kcal] } \\
\text { Calculated }\end{array}$ \\
\hline 1 & $60.18 \pm 2.8$ & $3.4 \pm 0.04$ & $38.24 \pm 1.33$ & 166.56 \\
\hline 2 & $61.21 \pm 1.4$ & $3.2 \pm 0.01$ & $41.56 \pm 2.76$ & 179.04 \\
\hline 3 & $59.97 \pm 3.2$ & $3.3 \pm 0.10$ & $36.84 \pm 3.53$ & 160.56 \\
\hline 4 & $60.58 \pm 2.4$ & $3.5 \pm 0.42$ & $38.24 \pm 2.13$ & 166.96 \\
\hline
\end{tabular}

Table 1: Nutritional value of product: [values are for $100 \mathrm{gm}$ of final product].

Each Values are mean of 6 trial \pm SE for each sample obtained.

non significant for all intermediate and variant sample. Values are depicted in table 1 . The weight of the tomatoes and output of the product are indicated in table 2. The values are non significant for all intermediate and variant sample. 


\begin{tabular}{|l|c|c|c|c|}
\hline & & \multicolumn{3}{|c|}{ Weight of the product. [Kg.] } \\
\hline Sample & Wt. of tomatoes [Kg.] & Trial 1 & Trial 2 & Trial 3 \\
\hline 1 & 1.024 & $1.38 \pm 6.4$ & $1.18 \pm 5.1$ & $1.28 \pm 7.2$ \\
\hline 2 & 1.098 & $1.16 \pm 4.4$ & $1.21 \pm 11.3$ & $1.24 \pm 3.5$ \\
\hline 3 & 1.102 & $0.980 \pm 10.9$ & $1.09 \pm 8.2$ & $0.950 \pm 6.2$ \\
\hline 4 & 1.118 & $1.10 \pm 3.5$ & $0.950 \pm 8.9$ & $1.17 \pm 8.4$ \\
\hline
\end{tabular}

Table 2: Processed Weight of the Product.

Each Values are mean of 6 trial \pm SE for each sample obtained.

These result indicates efficiency of machine which monitoring product quality with respect to constituency and proximate. These result indicates efficiency of machine which monitoring product quality with respect to constituency and proximate.

\section{Discussion}

The results of the study indicates very close relationship between trials and sample with respect to nutritional value. The efficiency of a machine was checked by processing tomatoes to obtain product. Product no. 3 has lowest weight of the final product followed by product no 4 , this variation may be due to higher perishability of tomatoes required to processed to obtain desired product.

\section{Conclusion}

Machine framed is first kind of innovation which can process ketchup and products thereof at small scale.it is cost efficient and will assuredly have good market demand as machine cost is also too low compare to output provided. It is suitable to arrange outside malls, restaurants like places as it is mobile production machine, it is easily movable. Total output remains to the $1.2 \mathrm{Kg}$. if around $1 \mathrm{Kg}$ of tomatoes are processed.

\section{Note}

Machine design is published for the patent.

\section{Bibliography}

1. www.nhb.gov.in/statistics/Reports/TomatoDecember2018. pdf

2. www.growtomatoes.com/tomato-world-production-statistics

3. https://extension.uga.edu/publications/detail. html?number=B1312

4. https://en.wikipedia.org/wiki/List_of_countries_by_tomato_ production

5. A.O.A.C. $15^{\text {th }}$ edition.

\section{Volume 3 Issue 10 October 2019}

(c) All rights are reserved by Shah Monarch J and Shah Harshada J. 